Article

\title{
Cinnamomum tamala leaf extract-mediated green synthesis of Ag nanoparticles and their use in pyranopyrazles synthesis
}

\author{
Sneha Yadav, Jitender M. Khurana* \\ Department of Chemistry, University of Delhi, Delhi110007, India
}

\section{A R T I C L E I N F O}

Article history:

Received 20 January 2015

Accepted 17 March 2015

Published 20 July 2015

Keywords:

Silver nanoparticle

Cinnamomum tamala leaf

Catalysis

Pyranopyrazole

\section{A B S T R A C T}

A novel, biochemical, and eco-friendly method has been developed for the synthesis of Ag nanoparticles using an aqueous leaf extract of readily accessible Cinnamomum tamala as reducing and stabilizing agents. These Ag nanoparticles were used to catalyze the synthesis of pyranopyrazoles. The green nature and ease of recovery and reusability of the catalyst, together with high yields of products, make this protocol attractive and useful.

(C) 2015, Dalian Institute of Chemical Physics, Chinese Academy of Sciences. Published by Elsevier B.V. All rights reserved.

\section{Introduction}

Nanomaterials display interesting biological, optical, magnetic, and catalytic properties, which differ from those of the bulk materials because of their small size. Noble-metal nanoparticles (NPs) have important applications in electronics, magnetic materials, optoelectronics, and information storage [1]. Ag NPs are excellent substrates for surface-enhanced Raman scattering [2] for probing single molecules, and are attractive building blocks for nanomaterial architectures [3]. Ag NPs have strong antibacterial [4,5] and anti-inflammatory properties [6]. Ag NPs can be synthesized using methods such as chemical reduction [7], electrochemical reduction [8], ultrasound-assisted reduction [9], photoinduced or photocatalytic reduction [10], microwave-assisted synthesis [11], microemulsion methods [12], and biochemical methods [13]. The focus in recent years has been on developing greener approaches to NP synthesis. The implementation of green chemistry principles in the synthesis of metal NPs can be achieved using multipurpose agents that perform both reduction and stabilization. The ex- ploration of plant extracts as potential reducing and stabilizing agents has heightened interest in the biological synthesis of NPs. Extracts from plants such as Capsicum annum [14], Aloe vera [15], Cinnamomum camphora [16], Acalypha indica [17], Emblica officinalis [18], Jatropha curcas [19], Musa paradisiacal [20], and Ocimum sanctum [21] have been used as reducing agents for the reduction of Ag ions to Ag. There have been a few reports of the use of Ag NPs as catalysts for oxidation and reduction of certain molecules [22-24], $\mathrm{A}^{3}$ coupling reactions [25], synthesis of $\beta$-enaminones [26], Diels-Alder cycloaddition [27], and hydrogenation of chloronitrobenzenes [28].

We have explored new and greener methods for Ag NP preparation. We focused on Cinnamomum tamala leaves, commonly known as Tejpat in India, and used extensively in cooking for their distinctive flavor and fragrance. One of the major components of the essential oil of $C$. tamala leaves is eugenol [29] (Scheme 1). Eugenol reduces $\mathrm{AgNO}_{3}$ because of the inductive effects of the methoxy and allyl groups positioned ortho and para to the proton-releasing - $\mathrm{OH}$ group, leading to the formation of the resonating structure of the anionic form of

* Corresponding author. Tel: +91-11-2766772; Fax: +91-1-27667624; E-mail: jmkhurana1@yahoo.co.in, jmkhurana@chemistry.du.ac.in DOI: 10.1016/S1872-2067(15)60853-1 | http://www.sciencedirect.com/science/journal/18722067 | Chin. J. Catal., Vol. 36, No. 7, July 2015 
<smiles>C=CCc1ccc(O)c(OC)c1</smiles>

4-Allyl-2-methoxy-phenol (Eugenol)

Scheme 1. Structure of eugenol.

eugenol [30].

We compared the properties of Ag NPs with those of NPs prepared by other methods, and explored potential new applications of Ag NPs as catalysts for multicomponent reactions.

\section{Experimental}

\subsection{Nanocatalyst preparation}

Dried C. tamala leaves (2 g) were washed thoroughly, crushed, and stirred with deionized water $(20 \mathrm{~mL})$ at $60{ }^{\circ} \mathrm{C}$ for 15-20 min. The solution was filtered and the filtrate was used as a green reductant and stabilizing agent.

In a typical experiment, an aqueous solution of $\mathrm{AgNO}_{3}(0.2$ $\mathrm{mmol} / \mathrm{L})$ was prepared. Leaf extract $(10 \mathrm{~mL})$ was added to the aqueous solution of $\mathrm{AgNO}_{3}(80 \mathrm{~mL})$ and the mixture was stirred with a magnetic stirrer in the dark at room temperature. After $1 \mathrm{~h}$, the color of the solution changed to light yellow, and then to orange-brown with continued stirring. The progress of the reaction was monitored by measuring the ultraviolet-visible (UV-Vis) absorbance (surface plasmon resonance) of the reaction mixture at regular time intervals.

\subsection{Characterization}

The reduction of $\mathrm{Ag}^{+}$ions was monitored by periodic sampling of aliquots $(1 \mathrm{~mL})$ of the aqueous reaction mixture. The optical absorbance of the Ag NPs was recorded in the range 300-500 nm using a Perkin Elmer Lambda 35 UV-Vis spectrophotometer. High-resolution transmission electron microscopy (HRTEM) and energy-dispersive X-ray spectroscopy (EDX) were performed (TECNAI G² U-TWIN; $300 \mathrm{kV}$ ) by drop coating Ag NPs on carbon-coated $\mathrm{Cu}$ grids. Ag NPs for X-ray diffraction (XRD) were prepared as follows. An Ag NP solution was subjected to repeated centrifugation at $6000 \mathrm{r} / \mathrm{min}$, and the isolated NPs were washed with absolute ethanol to remove the extract residues, and then coated as a thin film on a glass slide. The XRD pattern was obtained using a Brucker D8 instrument operated at $40 \mathrm{kV}$ and $40 \mathrm{~mA}$, with $\mathrm{Cu} K \alpha$ radiation $(\lambda=$ $0.15406 \mathrm{~nm})$.

\subsection{General procedure for synthesis of pyranopyrazole IIa-I}

Ag NPs (0.01 mmol) were added to a mixture of an aldehyde (1.0 mmol), ethyl acetoacetate $(1.0 \mathrm{mmol})$, hydrazine hydrate (1.0 mmol), and malononitrile $(1.0 \mathrm{mmol})$ in water $(5 \mathrm{~mL})$. The mixture was stirred at room temperature. The reaction progress was monitored by thin-layer chromatography (TLC), with petroleum ether/ethyl acetate (7:3) as the eluent. After completion of the reaction, the solid product was filtered using a pump, and washed and recrystallized with ethanol. The products were characterized based on spectroscopic data.

\subsection{General procedure for synthesis of pyranopyrazoles IIm- $\boldsymbol{q}$}

Ag NPs (0.01 mol) were added to a mixture of an aldehyde (1.0 mmol), ethyl acetoacetate $(1.0 \mathrm{mmol})$, phenylhydrazine (1.0 mmol), and malononitrile $(1.0 \mathrm{mmol})$ in water $(5 \mathrm{~mL})$. The mixture was stirred at $60{ }^{\circ} \mathrm{C}$. The reaction progress was monitored by TLC, with petroleum ether/ethyl acetate (7:3) as the eluent. After completion of the reaction, the solid product was filtered using a pump, and washed and recrystallized with ethanol. The products were characterized based on spectroscopic data.

\section{Results and discussion}

In the present study, we developed a new method for the preparation of $\mathrm{Ag} \mathrm{NPs}$ from aqueous $\mathrm{AgNO}_{3}$ solution, using $C$. tamala leaf extract as a reducing and stabilizing system. The Ag NPs were characterized using TEM, XRD, EDX, and UV-Vis spectroscopy. The Ag NPs obtained had sizes of $8 \pm 2 \mathrm{~nm}$, which is comparable to or smaller than those of NPs synthesized using other plant extracts.

The Ag NP synthesis was monitored by observing the color change of the reaction mixture. The change in the solution color to yellow-brown from colorless after $1 \mathrm{~h}$ indicated the formation of Ag NPs (Fig. 1(a)). The characteristic absorption peak
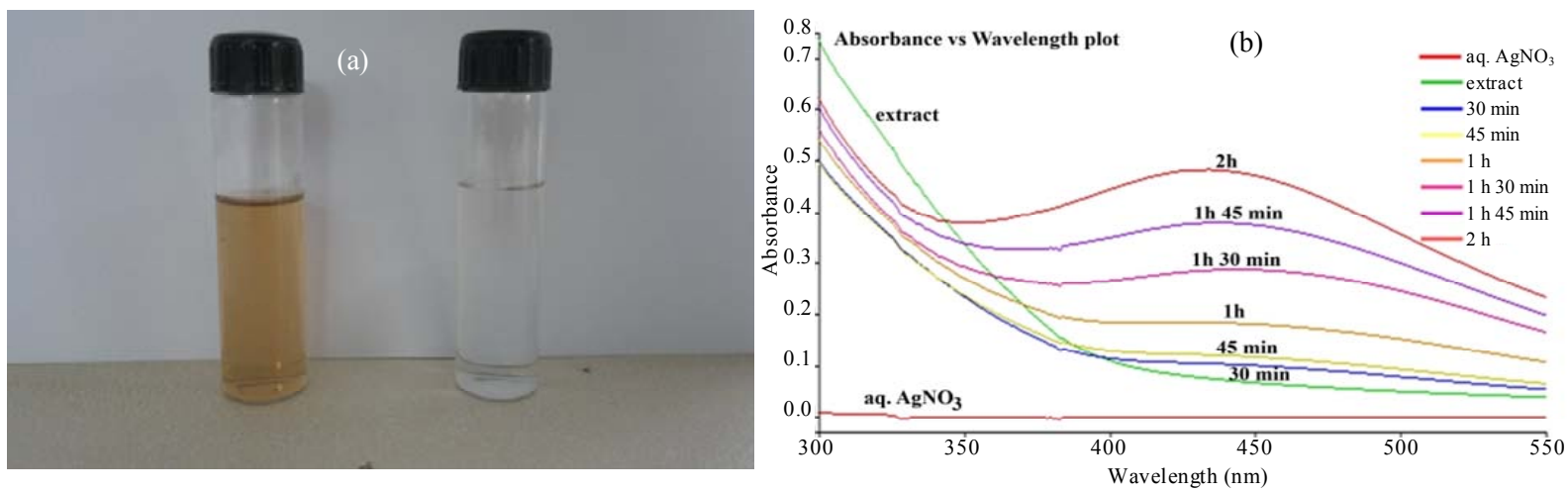

Fig. 1. (a) Color change after adding C. tamala leaf extract to aqueous solution of $0.2 \mathrm{mmol} / \mathrm{L} \mathrm{AgNO}_{3}$. (b) UV-Vis spectra of reaction mixture at different time intervals. 

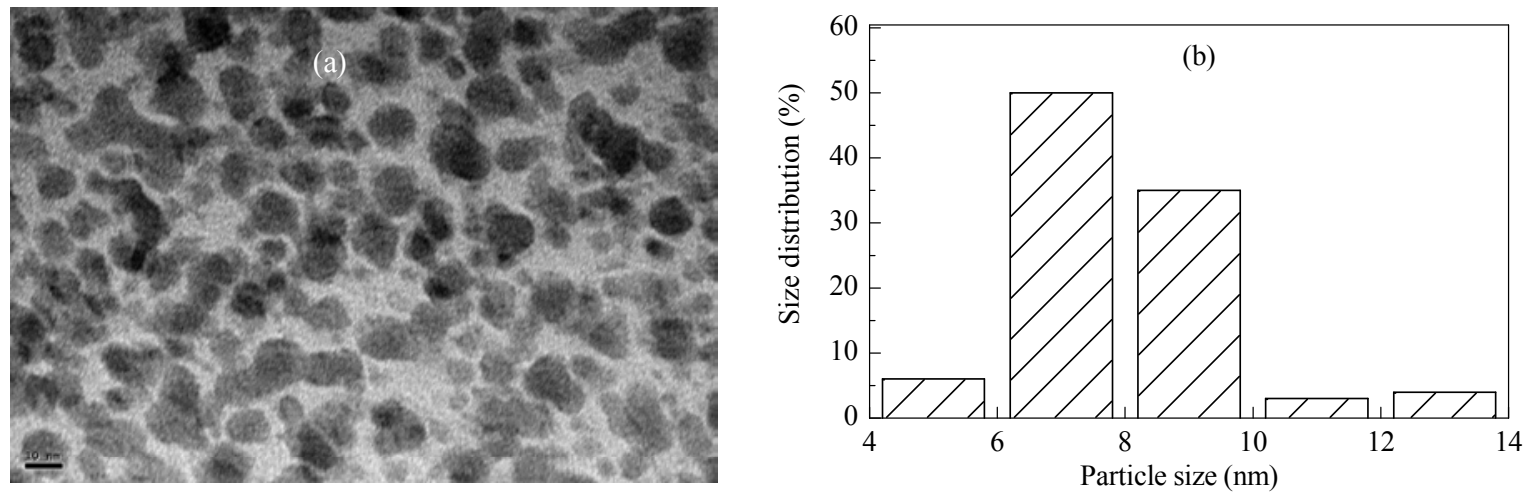

Fig. 2. (a) HRTEM image of Ag NPs; (b) histogram showing average sizes of Ag NPs.

at $440 \mathrm{~nm}$ in the UV-Vis spectrum confirmed the formation of Ag NPs. The intensity of the brown color increased in direct proportion to the stirring time. This may be because of the plasmon resonance displayed by Ag NPs. Fig. 1(b) shows the UV-Vis spectra of the solution as a function of reaction time.

A HRTEM image of the Ag NPs is shown in Fig. 2(a). The NPs were nearly spherical and measured 7-15 $\mathrm{nm}$. The histogram in Fig. 2(b) shows that the NPs were of average size $8 \pm 2 \mathrm{~nm}$. A list of various plant extracts that have been used for the preparation of Ag NPs, along with their respective sizes, is given in Table 1. EDAX showed a strong signal for Ag, confirming the formation of Ag NPs. Signals corresponding to $\mathrm{C}$ and $\mathrm{Cu}$ arose from the carbon-coated $\mathrm{Cu}$ grids used for the analysis (Fig. 3). The XRD pattern showed three distinct diffraction peaks, at $38.06^{\circ}, 44.02^{\circ}$, and $64.36^{\circ}$, which were indexed to the (111), (200), and (220) planes of cubic face-centered Ag. The formation of $\mathrm{Ag}(0)$ was therefore confirmed. The additional unassigned peaks in Fig. 4 can be attributed to crystallization of bioorganic phases on the NP surfaces [31-34]. The average Ag $\mathrm{NP}$ grain size was estimated to be $20 \mathrm{~nm}$ using the Scherrer equation.

We then focused on using aqueous dispersions of these Ag NPs as green catalytic systems for multicomponent reactions. We investigated the synthesis of pyranopyrazoles [36-39] via a four-component condensation. The reaction of 4-chlorobenzaldehyde $(1.0 \mathrm{mmol})$, malononitrile $(1.0 \mathrm{mmol})$, ethyl acetoacetate $(1.0 \mathrm{mmol})$, and hydrazine hydrate $(1.0 \mathrm{mmol})$ in water (5 $\mathrm{mL}$ ) was performed at room temperature, using various amounts of catalyst (Ag NPs). The reaction with $0.01 \mathrm{mmol}$ of Ag NPs gave 6-amino-4-(4-chlorophenyl)-3-methyl-2,4-dihydropyrano[2,3-c]pyrazole-5-carbonitrile (IIa) in 92\% yield in 15 min. Reactions with lower concentrations of Ag NPs resulted

\section{Table 1}

Plant extracts reported for use in synthesis of Ag NPs, and corresponding Ag NP sizes.

\begin{tabular}{lc}
\hline Plant Extract & Ag NPs size (nm) \\
\hline C. camphora [16] & 64.8 \\
A. indica [17] & $20-30$ \\
E. officinalis [18] & $10-20$ \\
I. curcas [19] & $20-40$ \\
C. annum [14] & $10 \pm 2$ \\
A. vera [15] & $15.2 \pm 4.2$ \\
S. aromaticum [35] & $20-149$ \\
\hline
\end{tabular}

in lower product yields, and higher molar concentrations did not substantially improve the yield or reaction time. The reaction scope was extended by performing the reaction with phenylhydrazine instead of hydrazine hydrate, under similar reaction conditions. However, the reaction was incomplete after prolonged stirring at room temperature. When the catalyst loading was increased, the reaction still did not go to completion. The reactions were then performed at higher temperatures, and this improved the results. The reaction using phenylhydrazine was complete in $30 \mathrm{~min}$ at $60^{\circ} \mathrm{C}$ and yielded $90 \%$ of IIm, without altering the catalyst loading. The optimized conditions were then used to study the generality of the reaction by screening a wide range of aldehydes (Scheme 2). The reaction proceeded smoothly with various aldehydes, giving

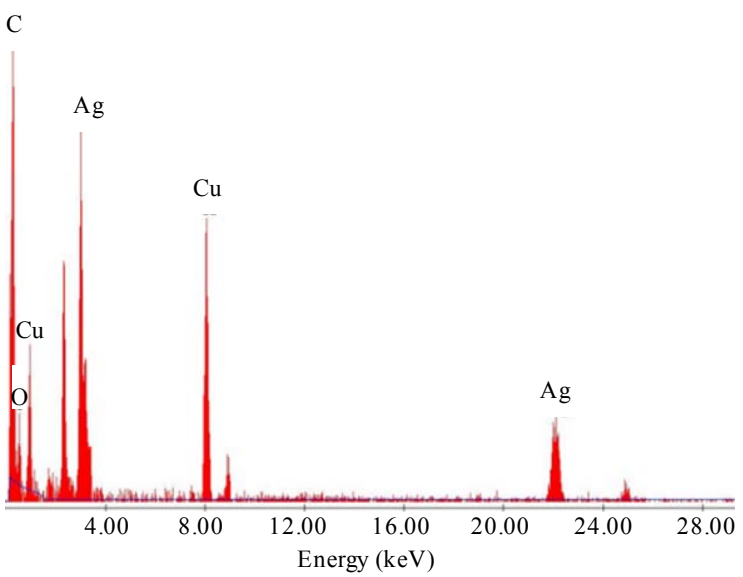

Fig. 3. EDX spectrum of Ag NPs synthesized using C. tamala leaf extract.

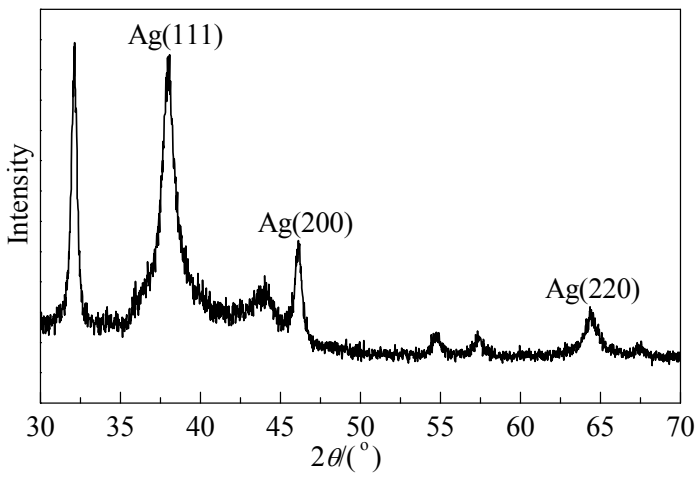

Fig. 4. XRD pattern of synthesized Ag NPs. 


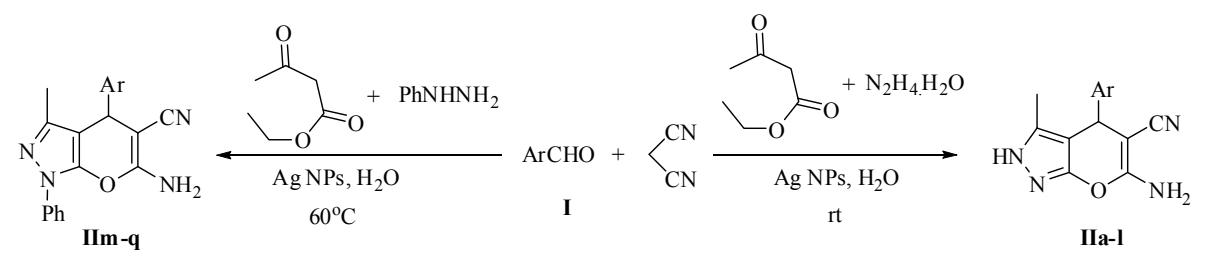

Scheme 2. Ag-NP-catalyzed synthesis of pyranopyrazoles.

Table 2

Ag-NP-catalyzed synthesis of pyranopyrazole derivatives by condensation of aldehydes, malononitrile, ethyl acetoacetate, and hydrazine hydrate ${ }^{[a]} /$ phenylhydrazine ${ }^{[b]}$.

\begin{tabular}{|c|c|c|c|c|}
\hline Entry & $\mathrm{Ar}-\mathrm{CHO}(\mathrm{I}) \mathrm{Ar}$ & Product (II) & Time (min) & Yield (\%) \\
\hline 1 & $4-\mathrm{ClC}_{6} \mathrm{H}_{5}$ (Ia) & IIa & 15 & 92 \\
\hline 2 & $4-\mathrm{C}_{6} \mathrm{H}_{4}(\mathbf{I b})$ & IIb & 15 & 90 \\
\hline 3 & $4-\mathrm{O}_{2} \mathrm{NC}_{6} \mathrm{H}_{4}(\mathrm{Ic})$ & IIc & 20 & 93 \\
\hline 4 & $4-\mathrm{FC}_{6} \mathrm{H}_{4}(\mathbf{I d})$ & IId & 25 & 92 \\
\hline 5 & $3,4,5-\left(\mathrm{CH}_{3} \mathrm{O}\right)_{3} \mathrm{C}_{6} \mathrm{H}_{2}(\mathbf{I e})$ & IIe & 10 & 93 \\
\hline 6 & 2-Furanyl (If) & IIf & 25 & 93 \\
\hline 7 & 2-Naphthyl (Ig) & IIg & 20 & 90 \\
\hline 8 & $2,4-\mathrm{Cl}_{2} \mathrm{C}_{6} \mathrm{H}_{3}$ (Ih) & IIh & 30 & 88 \\
\hline 9 & $3-\mathrm{HOC}_{6} \mathrm{H}_{4}(\mathbf{I i})$ & IIi & 25 & 95 \\
\hline 10 & $4-\mathrm{CH}_{3} \mathrm{C}_{6} \mathrm{H}_{4}(\mathbf{I j})$ & IIj & 15 & 91 \\
\hline 11 & $4-(\mathrm{HO})-3-(\mathrm{MeO}) \mathrm{C}_{6} \mathrm{H}_{3}(\mathbf{I k})$ & IIk & 25 & 94 \\
\hline 12 & $2,5-\left(\mathrm{CH}_{3} \mathrm{O}\right)_{2} \mathrm{C}_{6} \mathrm{H}_{4}(\mathrm{II})$ & IIl & 30 & 90 \\
\hline 13 & 4- $\mathrm{ClC}_{6} \mathrm{H}_{4}$ (Ia) & IIm & 30 & 89 \\
\hline 14 & $4-\mathrm{O}_{2} \mathrm{NC}_{6} \mathrm{H}_{4}(\mathbf{I c})$ & IIn & 35 & 90 \\
\hline 15 & $3,4-\left(\mathrm{CH}_{3} \mathrm{O}\right)_{2} \mathrm{C}_{6} \mathrm{H}_{4}(\mathbf{I m})$ & IIo & 25 & 91 \\
\hline 16 & $4-(\mathrm{HO})-3-\left(\mathrm{MeO}^{2} \mathrm{C}_{6} \mathrm{H}_{3}(\mathbf{I k})\right.$ & IIp & 25 & 93 \\
\hline 17 & $4-\mathrm{BrC}_{6} \mathrm{H}_{4}(\mathbf{I n})$ & IIq & 30 & 90 \\
\hline
\end{tabular}

Reactions carried out at ${ }^{[a]}$ room temperature and $\left[{ }^{[b]} 60^{\circ} \mathrm{C}\right.$, respectively.

the products in excellent yields in 15-35 min. The results are summarized in Table 2.

A reasonable mechanism for the synthesis of the pyranopyrazoles via a tandem Knoevenagel-cyclocondensation is outlined in Scheme 3.

The catalytic role of the Ag NPs was verified by a control experiment, which was conducted in water in the absence of

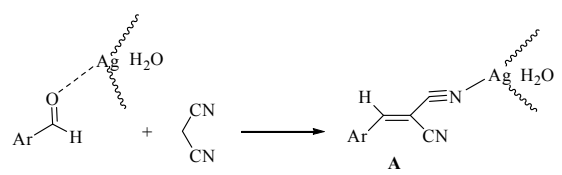<smiles>CCOC(=O)CC(C)=O</smiles>

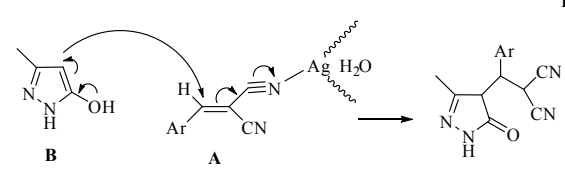

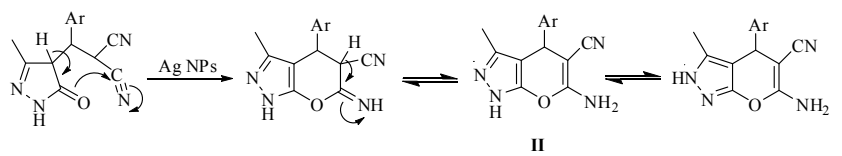

Scheme 3. Possible reaction pathway for synthesis of dihydropyrano[2,3-c]pyrazole derivatives in presence of Ag NPs.
NPs. The reaction of 4-chlorobenzaldehyde (1.0 mmol), malononitrile $(1.0 \mathrm{mmol})$, ethyl acetoacetate $(1.0 \mathrm{mmol})$, and hydrazine hydrate $(1.0 \mathrm{mmol})$ in water $(5 \mathrm{~mL})$ was incomplete after $8 \mathrm{~h}$ and yielded only 25\% of IIa. Moreover, the reaction with $\mathrm{AgNO}_{3}$ in water was sluggish and only $22 \%$ of the desired product Ila was obtained. These results support the involvement of Ag NPs in the formation of pyranopyrazoles.

Catalyst recovery and reusability are important aspects of green synthesis. These properties of the Ag NPs were investigated by solvent extraction of the product with ethyl acetate. The aqueous layer containing Ag NPs was then reused to conduct the reaction under the original reaction conditions. The reaction yields showed that the recycled NP catalyst could be repeatedly used for four consecutive cycles without any significant loss in activity, after which a drop in yield was observed (Fig. 5).

\section{Conclusions}

We have developed an eco-friendly, non-toxic, and cost-effective method for the synthesis of Ag NPs, using C. tamala leaf extract in water. The Ag NPs dispersed in water were used as a green catalytic system for the synthesis of pyranopyrazoles in
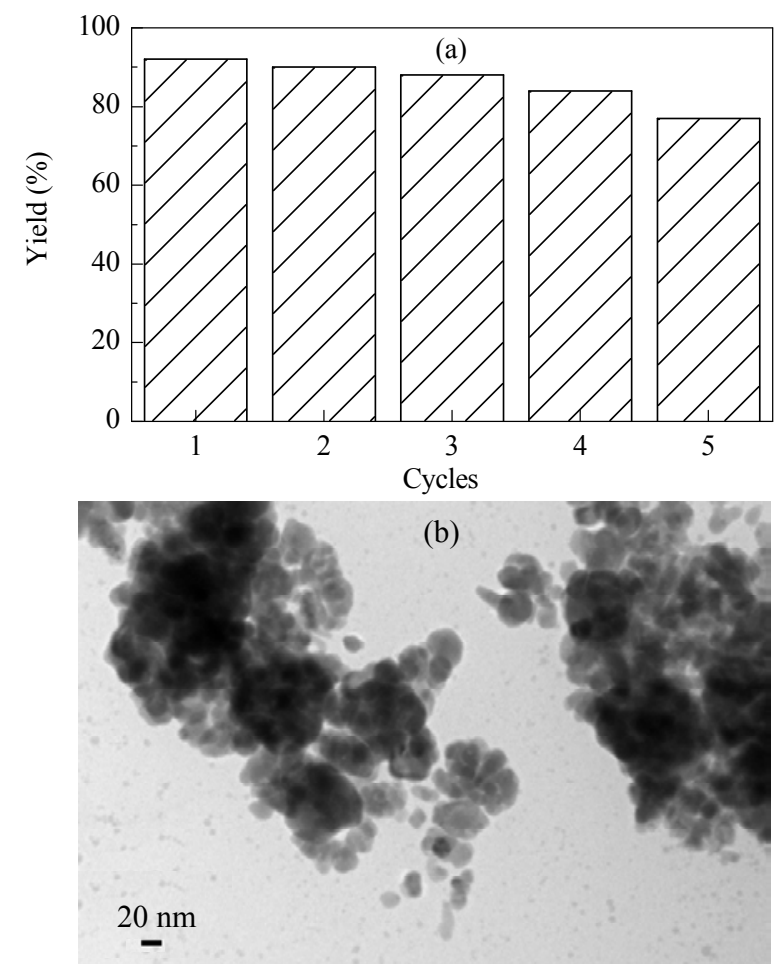

Fig. 5. (a) Plot of number of cycles against isolated yield; (b) TEM image of Ag NPs after four cycles. 


\section{Graphical Abstract}

Chin. J. Catal., 2015, 36: 1042-1046 doi: 10.1016/S1872-2067(15)60853-1

\section{Cinnamomum tamala leaf extract-mediated green synthesis of $\mathrm{Ag}$ nanoparticles and their use in pyranopyrazles synthesis}

Sneha Yadav, Jitender M. Khurana* University of Delhi, India

A novel, biochemical, and eco-friendly method was developed for the synthesis of Ag nanoparticles, using an aqueous leaf extract of Cinnamomum tamala as reducing and stabilizing agents. The Ag nanoparticles efficiently catalyzed pyranopyrazole synthesis.

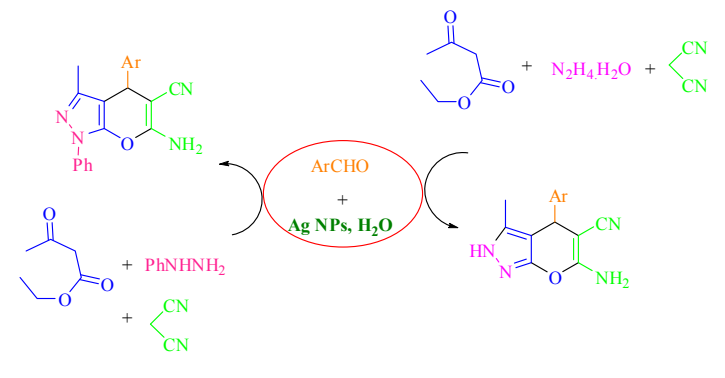

quantitative yields under mild reaction conditions.

\section{Acknowledgments}

Sneha is thankful to Council of Scientific and Industrial Research (CSIR), New Delhi, India for the award of Senior Research Fellowship and University Science Instrumentation Center (USIC), University of Delhi for providing instrumentation facilities.

\section{References}

[1] Okuda M, Kobayashi Y, Suzuki K, Sonoda K, Kondoh T, Wagawa A, Kondo A, Yoshimura H. Nano Lett, 2005, 5:991

[2] Tao A, Kim F, Hess C, Goldberger J, He R, Sun Y, Xia Y, Yang P. Nano Lett, 2003 3: 1229

[3] Shipway A N, Katz E, Willner I. ChemPhysChem, 2000, 1: 18

[4] Feng Q L, Wu J, Chen G Q, Kim T N, Kim J O. J Biomed Mater Res, 2000, 52: 662

[5] Liau S Y, Read D C, Pugh W J, Furr J R, Russell A D. Lett Appl Microbiol, 1997, 25: 279

[6] Wong K K Y, Cheung S O F, Huang L M, Niu J, Tao C, Ho C M, Che C M, Tam P K. ChemMedChem, 2009, 4: 1129

[7] Leopold N, Lendl B. J Phys Chem B, 2003, 107: 5723

[8] Zhang Y H, Chen F, Zhuang J H, Tang Y, Wang D J, Wang Y J, Dong A G, Ren N. Chem Commun, 2002: 2814

[9] Zhang J P, Sheng L Q, Chen P. Chin Chem Lett, 2003, 14: 645

[10] Shchukin D G, Radtchenko I L, Sukhorukov G B. ChemPhysChem, 2003, 4: 1101

[11] He B L, Tan J J, Liew K Y, Liu H F. J Mol Catal A, 2004, 221: 121

[12] McLeod M C, McHenry R S, Beckman E J, Roberts C B. J Phys Chem $B, 2003,107: 2693$

[13] Kowshik M, Ashtaputre S, Kharrazi S, Vogel W, Urban J, Kulkarni S K, Paknikar K M. Nanotechnology, 2003, 14: 95

[14] Li S K, Shen Y H, Xie A J, Yu X R, Qiu L G, Zhang L, Zhang Q F. Green Chem, 2007, 9: 852

[15] Chandran S P, Chaudhary M, Pasricha R, Ahmad A, Sastry M. Biotechnol Progr, 2006 22: 577

[16] Huang J L, Li Q B, Sun D H, Lu Y H, Su Y B, Yang X, Wang H X, Wang Y P, Shao W Y, He N, Hong J Q, Chen C X. Nanotechnology, 2007,
18: 105104

[17] Krishnaraj C, Jagan E G, Rajasekar S, Selvakumar P, Kalaichelvan P T, Mohan N. Colloids Surf B, 2010, 76: 50

[18] Ankamwar B, Damle C, Ahmad A, Sastry M. J Nanosci Nanotechnol, 2005, 10: 1665

[19] Bar H, Bhui D K, Sahoo G P, Sarkar P, De S P, Misra A. Colloids Surf A, 2009, 339: 134

[20] Bankar A, Joshi B, Kumar A R, Zinjarde S. Colloids Surf A, 2010, 368: 58

[21] Ahmad N, Sharma S, Alam M K, Singh V N, Shamsi S F, Mehta B R, Fatma A. Colloids Surf B, 2010, 81: 81

[22] Sanpui P, Murugadoss A, Prasad P V D, Ghosh S S, Chattopadhyay A. Int J Food Microbiol, 2008, 124: 142

[23] Murugadoss A, Chattopadhyay A. J Phys Chem C, 2008, 112: 11265

[24] Yan W J, Wang R, Xu Z Q, Xu J K, Lin L, Shen Z Q, Zhou Y F. J Mol Catal A, 2006, 255: 81

[25] Yong G P, Tian D, Tong H W, Liu S M. J Mol Catal A, 2010, 323: 40

[26] Bhatte K D, Tambade P J, Dhake K P, Bhanage B M. Catal Commun, 2010, 11: 1233

[27] Cong H. Becker C F, Elliott S J, Grinstaff M W, Porco J A. J Am Chem Soc, 2010, 132: 7514

[28] Chen Y Y, Wang C, Liu H Y, Qiu J S, Bao X H. Chem Commun, 2005: 5298

[29] Rema J, Leela N K, Krishnamoorthy B, Mathew P A. J Med Aromat Plant Sci, 2005, 27: 515

[30] Singh A K, Talat M, Singh D P, Srivastava O N. J Nanopart Res, 2010, 12: 1667

[31] Khalil M M H, Ismail E H, El-Baghdady K Z, Mohamed D. Arab J Chem, 2014, 7: 1131

[32] Karuppiah M, Rajmohan R. Mater Lett, 2013, 97: 141

[33] Philip D, Unni C. Phys E, 2011, 43: 1318

[34] Kalimuthu K, Babu R S, Venkataraman D, Bilal M, Gurunathan S. Colloids Surf B, 2008, 65: 150

[35] Vijayaraghavan K, Nalini S P, Prakash N U, Madhankumar D. Mater Lett, 2012, 75: 33

[36] Swaroop T R, Sharath Kumar K S, Palanivelu M, Chaitanya S, Rangappa K S. J Heterocycl Chem, 2014, 51: 1866

[37] Wu M S, Feng Q Q, Wan D H, Ma J Y. Synth Commun, 2013, 43: 1721

[38] Vasuki G, Kumaravel K. Tetrahedron Lett, 2008, 49: 5636

[39] Kanagaraj K, Pitchumani K. Tetrahedron Lett, 2010, 51: 3312 